06.1

\title{
Новый гибридный материал монолитный биоморфный углерод/наночастицы никеля для устройств накопления энергии
}

\author{
(ㄱ Т.С. Орлова ${ }^{1}$, А.А. Спицын², Д.А. Пономарев ${ }^{2}$, Д.А. Кириленко ${ }^{1,3}$, А.Е. Романов ${ }^{1,3}$ \\ ${ }^{1}$ Физико-технический институт им. А.Ф. Иоффре РАН, Санкт-Петербург, Россия \\ ${ }^{2}$ Санкт-Петербургский лесотехнический университет, Санкт-Петербург, Россия \\ ${ }^{3}$ Санкт-Петербургский национальный исследовательский университет информационных технологий, механики и оптики \\ (Университет ИТМО), Санкт-Петербург, Россия \\ E-mail: orlova.t@mail.ioffe.ru
}

Поступило в Редакцию 23 апреля 2019г.

В окончательной редакции 15 мая 2019г.

Принято к публикации 15 мая 2019г.

Простым, дешевым и экологически совместимым способом получен новый гибридный материал bioC/NiNPs, представляющий собой высокопористую частично графитизированную углеродную матрицу (bioC) с равномерно нанесенными наночастицами никеля (NiNPs) размером 5-70 nm. Методами просвечивающей электронной микроскопии показано, что углеродная матрица состоит преимущественно из углерода луковичной формы с полыми капсулами/порами размером около $5 \mathrm{~nm}$, в ней также присутствуют глобулы графита размером до $200 \mathrm{~nm}$. Композит bioC/NiNPs продемонстрировал высокую электрохимическую емкость и ее высокую стабильность в пределах 1000 циклов зарядки-разрядки, что позволяет рассматривать его как перспективный материал для применения в качестве монолитных электродов для суперконденсаторов.

Ключевые слова: гибридные углеродные материалы, нанокомпозиты, микроструктура, электрохимическая емкость.

DOI: 10.21883/PJTF.2019.16.48149.17852

В связи с растущим потреблением энергии, проблемами загрязнения окружающей среды и глобального потепления все большее внимание привлекают экологически чистые, благоприятные для окружающей среды методы получения и хранения энергии. В цепи получения-хранения-потребления энергии важную роль играют суперконденсаторы благодаря высокой удельной мощности, длительному сроку службы и относительно широкой области рабочих температур $[1,2]$. Электрохимическая емкость суперконденсатора в значительной степени зависит от характеристик материала электрода. В двойнослойных суперконденсаторах ELDC (electrical double layer capacitors) для электродов используются главным образом углеродные материалы, так как они обладают хорошей электропроводностью, высокой открытой пористостью, обеспечивающей большую удельную поверхность, химической стабильностью и имеют относительно низкую стоимость. Большинство углеродных материалов с высокой удельной поверхностью получают в виде порошков, поэтому для приготовления из них электродов требуются связующие вещества, которые могут значительно уменьшать площадь электрохимически активной поверхности материала, а также понижать электропроводность материала. В связи с этим проводятся исследования по получению монолитных высокопористых углеродных материалов для использования их в качестве электродов без связующих добавок (аэрогелей [3,4], микропористых активированных угольных монолитов, синтезированных из мезофазной смолы $[5,6])$. Все большее внимание уделяется так называемым „зеленым технологиям“ получения материалов для электродов к суперконденсаторам. Среди них особую нишу занимают активированные монолитные биоморфные углероды, карбонизированные из природной древесины, например активированная паром карбонизированная древесина бука [7], частично графитизированные биоуглероды, полученные с использованием Fе-содержащего катализатора [8], химически активированные монолитные биоуглероды, полученные из древесины тополя [9] и гевеи [10]. Однако полученные значения емкости для таких структур остаются недостаточно высокими. Развитая открытая пористость таких углеродных матриц позволяет внести в поры углерода дополнительные электрохимически активные компоненты (наночастицы металлов/оксидов металлов) в большом количестве и создать гибридные композитные материалы с увеличенной электрохимической емкостью за счет дополнения ELDC-емкости псевдоемкостными процессами [11].

В настоящей работе получен такой гибридный материал, состоящий из активированной монолитной биоуглеродной матрицы bioC и наночастиц металлического никеля (NiNPs) на еe развитой пористой поверхности. Композит bioC/NiNPs был приготовлен простым экологически благоприятным способом на основе древесины березы. Древесина березы высушивалась при $105-110^{\circ} \mathrm{C}$ до момента прекращения изменения массы, затем нарезалась на кубики со стороной около $10 \mathrm{~mm}$, которые выдерживались в $1 \mathrm{M}$ водном растворе нитрата никеля (II) в течение $120 \mathrm{~h}$. Затем пропитанные 


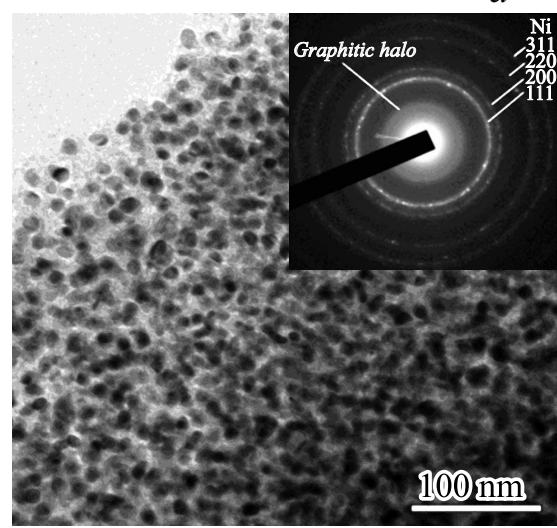

$b$

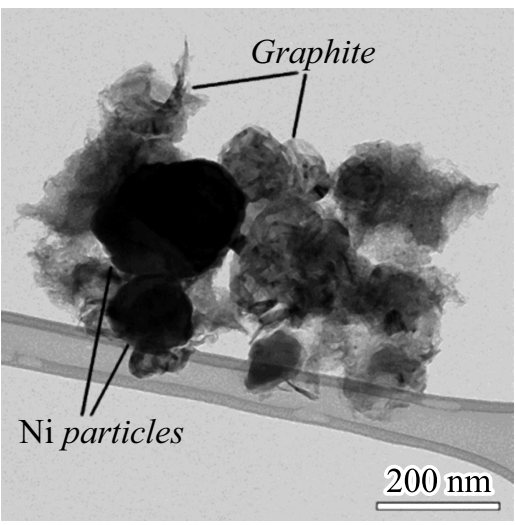

$c$

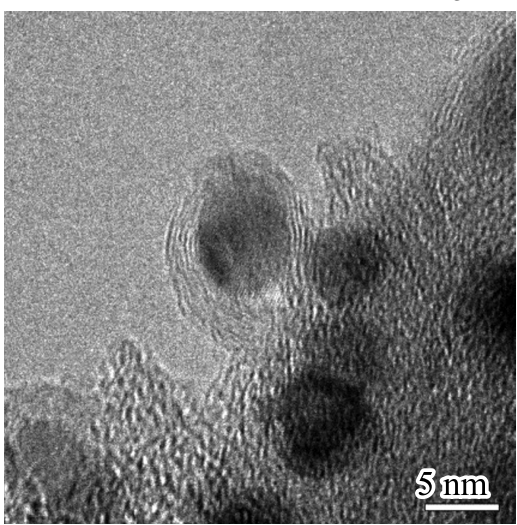

Рис. 1. ПЭМ-изображения гибридного материала bioC/NiNPs. $a$ - типичные наночастицы Ni в углеродной матрице с соответствующей дифракционной картиной; $b-$ более крупные частицы никеля и частицы графита, $c-$ наночастицы никеля, окруженные углеродом луковичной формы.

кубики, предварительно высушенные при температуре $105-110^{\circ} \mathrm{C}$ до постоянной массы, карбонизировались в процессе нагрева до температуры $970^{\circ} \mathrm{C}$ в закрытом реакторе из нержавеющей стали (с отводом парогазов) со скоростью нагрева $2{ }^{\circ} \mathrm{C} \cdot \min ^{-1}$ в атмосфере самогенерируемых парогазов. После достижения $970^{\circ} \mathrm{C}$ реактор охлаждался до комнатной температуры также в атмосфере парогазов в течение $2 \mathrm{~h}$. В процессе нагрева до $970^{\circ} \mathrm{C}$ происходила карбонизация древесины, а нитрат никеля превращался в металлический никель в соответствии с уравнениями [12]:

$$
\begin{gathered}
2\left(\mathrm{Ni}\left(\mathrm{NO}_{3}\right)_{2} \cdot 6 \mathrm{H}_{2} \mathrm{O}\right) \rightarrow 2 \mathrm{NiO}+4 \mathrm{NO}_{2}+\mathrm{O}_{2}+12 \mathrm{H}_{2} \mathrm{O}, \\
\mathrm{NiO}+\mathrm{C} \rightarrow \mathrm{Ni}+\mathrm{CO}
\end{gathered}
$$

Различие в массах между пропитанным высушенным и исходным образцами древесины приходится на массу нитрата никеля (II) $m_{\left.\left(\mathrm{Ni}_{(} \mathrm{NO}_{3}\right)_{2}\right) \cdot 6 \mathrm{H}_{2} \mathrm{O}} \cdot \mathrm{B}$ предположении, что весь оксид никеля (II) восстанавливается до свободного никеля согласно уравнению (2) [12], была определена совокупная масса никеля $m_{\mathrm{Ni}}$.

Структурная характеризация полученного композита bioC/NiNPs проводилась методами рентгеновского дифракционного анализа на рентгеновских дифрактометрах D8 Discover (Bruker) и D2 Phaser (Bruker) и методами просвечивающей электронной микроскопии (ПЭМ) с использованием микроскопа Jeol JEM-2010F (ускоряющее напряжение $200 \mathrm{kV}$, разрешение по точкам $0.19 \mathrm{~nm})$.

Полученный композитный материал bioC/NiNPs разрезался на пластины размером $9 \times 3 \mathrm{~mm}$ и толщиной $\sim 1.5 \mathrm{~mm}$, которые исследовались в качестве электрода в электрохимических полуячейках. В качестве электролита использовался $3 \mathrm{M}$ водный раствор КОН. Электрохимические измерения проводились с использованием гальваностата-потенциостата Elins P20X в трехэлектродной ячейке с рабочим электродом bioC/NiNPs, электродом сравнения $\mathrm{Ag} / \mathrm{AgCl}$ (измеренные потенциалы даны относительно этого электрода) и платиновым вспомогательным электродом с площадью, превышающей площадь рабочего электрода. Измерения циклической вольтамперометрии (CV) выполнялись при различных скоростях изменения (развертки) потенциала $v$ от 1 до $100 \mathrm{mV} \cdot \mathrm{s}^{-1}$ в интервале $0-0.5 \mathrm{~V}$. Эксперименты по гальваностатическому заряду-разряду были выполнены при разной плотности тока и изменении потенциала от 0 до $0.5 \mathrm{~V}$.

B CV-экспериментах дифференциальная удельная емкость $C_{\mathrm{CV}}\left[\mathrm{F} \cdot \mathrm{g}^{-1}\right]$ определялась как $C_{\mathrm{CV}}=I /(v m)$, где $I-$ ток, $v=d V / d t$ - скорость развертки потенциала, $t$ - время, $m$ - масса электрода или активного материала в электроде. В экспериментах гальваностатического заряда-разряда удельная электрохимическая емкость определялась согласно уравнению

$$
C_{\mathrm{GCD}}=I \Delta t /(m \Delta V) .
$$

$I$ - величина тока разряда (заряда), $m$ - масса электрода (или активного вещества в электроде), $\Delta t-$ время разряда, $\Delta V$ - изменение потенциала в течение разрядки.

Исследования методами ПЭМ показали, что композит представляет собой высокопористую углеродную матрицу с наночастицами $\mathrm{Ni}$ размером 5-70 nm, относительно равномерно распределенными по ее 3D-пористой поверхности (рис. 1,a). Кроме того, в образце встречалось небольшое количество относительно крупных частиц никеля размером до $200 \mathrm{~nm}$ (рис. 1, $b$ ). Использование Ni-содержащих катализаторов при карбонизации древесины приводит к формированию нанопор в получаемой углеродной матрице [13]. В образцах bioC/NiNPs дополнительно к пористости исходной древесины формировались нанопоры, представляющие собой преимущественно полые капсулы (размером $\sim 5 \mathrm{~nm})$, окруженные углеродом луковичной формы, некоторые из них содержали частицы никеля малых размеров (рис. 1,c). Помимо углерода луковичного типа в углеродной матрице 

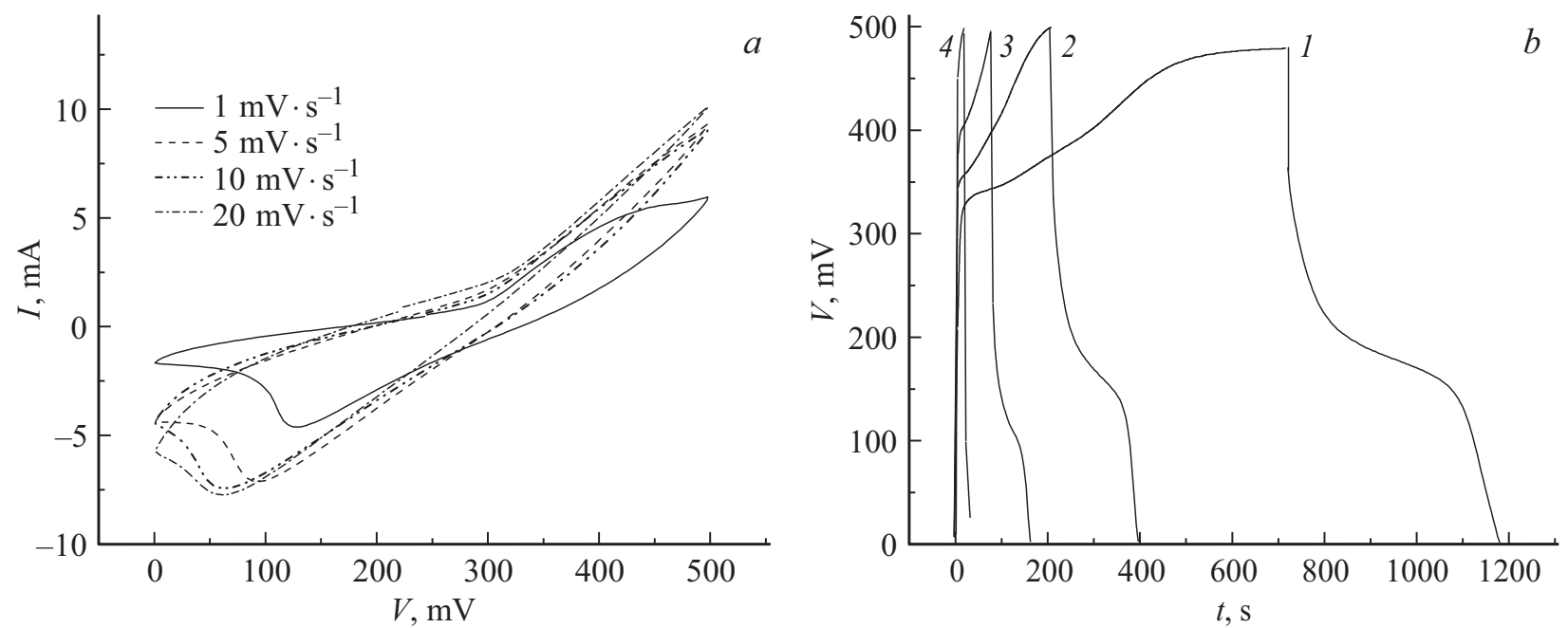

Рис. 2. $a$ - кривые циклической вольтамперометрии для образцов bioC/NiNPs, полученные при разных скоростях развертки потенциала; $b-$ кривые заряда-разряда для образцов bioC/NiNPs, полученные в гальваностатическом режиме при токах $I=0.15$ $(1), 0.25(2) 0.40(3), 0.55 \mathrm{~A} \cdot \mathrm{g}^{-1}(4)$ в расчете на полную массу электрода.

присутствовали глобулярные частицы графита размером до $200 \mathrm{~nm}$ (рис. $1, b)$, а также аморфный углерод. Присутствие металлического никеля и графитизированного углерода в композите bioC/NiNPs было подтверждено также проведенным в работе рентгеноструктурным анализом (РСА). Исследования методами ПЭМ и РСА не обнаружили присутствия оксида никеля, что свидетельствует о полной степени превращения его в металлический никель согласно уравнению (2).

На рис. 2, $a$ приведены типичные кривые циклической вольтамперометрии (I-V-кривые) при разных скоростях развертки потенциала для композита bioC/NiNPs. $I-V$-кривые для нанокомпозита имеют пики, характерные для окислительно-восстановительных реакций, что свидетельствует о псевдоемкостном характере накопления заряда. При $v=1 \mathrm{mV} \cdot \mathrm{s}^{-1}$ пик наблюдается при значении потенциала $V \approx 125 \mathrm{mV}$ и смещается в сторону меньших значений $V$ при увеличении скорости развертки потенциала. Процесс заряда происходит согласно прямой реакции

$$
\mathrm{Ni}+2 \mathrm{OH}^{-} \leftrightarrow \alpha-\mathrm{Ni}(\mathrm{OH})_{2}+2 e^{-},
$$

a разряда -- согласно обратной реакции [14]. Нанокомпозит bioC/NiNPs продемонстрировал высокую максимальную емкость $415 \mathrm{~F} \cdot \mathrm{g}^{-1}$ при скорости развертки потенциала $1 \mathrm{mV} \cdot \mathrm{s}^{-1}$, отнесенную к массе всего электрода (см. рис. 2, $a$ и таблицу).

Для сравнения $\mathrm{CV}$-измерения также были выполнены для образцов bioC, полученных в тех же условиях карбонизации древесины березы только в отсутствие Ni-содержащего катализатора. Максимальная емкость в этом случае не превышала $4.7 \mathrm{~F} \cdot \mathrm{g}^{-1}$ при скорости развертки потенциала $1 \mathrm{mV} \cdot \mathrm{s}^{-1}$. Карбонизированная древесина березы без использования катализатора повторяет пористую структуру исходной древесины, в которой

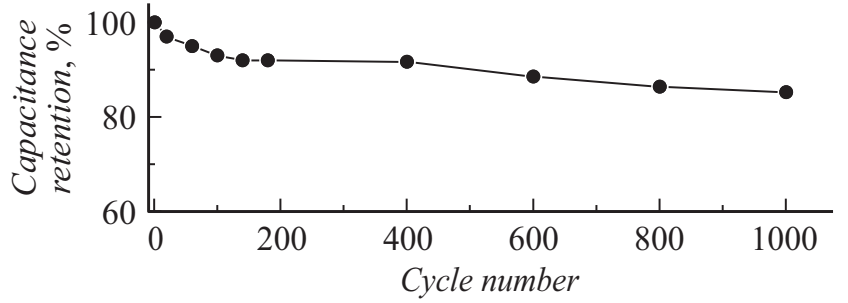

Рис. 3. Относительное изменение емкости электрода bioC/NiNPs в зависимости от количества циклов вольтамперометрии при скорости развертки потенциала $10 \mathrm{mV} \cdot \mathrm{s}^{-1}$.

суммарная пористость достигает 70\% и состоит главным образом из канальных пор двух типов с размерами 5-10 и $50-90 \mu \mathrm{m}[15]$, что не может обеспечить высокую удельную площадь поверхности и объясняет очень низкое значение электрохимической емкости, получаемой в случае bioC только за счет формирования двойного электрического слоя.

Кривые заряда-разряда, полученные в гальваностатическом режиме для композита bioC/NiNPs, показаны на рис. 2, $b$. Они имеют нелинейный характер, что свидетельствует о прохождении псевдоемкостных процессов. В экспериментах по гальваностатическому заряду-разряду максимальная удельная емкость $C_{\mathrm{GCD}}=215 \mathrm{~F} \cdot \mathrm{g}^{-1}$, отнесенная к массе всего электрода, была получена при плотности тока $I=0.15 \mathrm{~A} \cdot \mathrm{g}^{-1}$. Следует отметить, что, несмотря на введенную дополнительную нанопористость, вклад в электрохимическую емкость от ELDC (от углеродной матрицы) невелик. Высокая емкость нанокомпозита bioC/NiNPs обеспечена главным образом окислительно-восстановительными процессами на наночастицах $\mathrm{Ni}$ (рис. 2). Полученные емкостные характеристики электрода bioC/NiNPs, отне- 
Электрохимическая емкость композита bioC/NiNPs, отнесенная к массе всего электрода и к суммарной массе наночастиц никеля (NiNPs).

\begin{tabular}{c|c|c}
\hline & $\begin{array}{c}\text { Емкость, } \\
\text { отнесенная к } \\
\text { полной массе } \\
\text { Улектрода, } \mathrm{F} \cdot \mathrm{g}^{-1}\end{array}$ & $\begin{array}{c}\text { Емкость, отнесенная к } \\
\text { массе активного вещества } \\
(\mathrm{NiNPs}), \\
\mathrm{F} \cdot \mathrm{g}^{-1}\end{array}$ \\
\hline$C_{\mathrm{CV} \text { при } 1 \mathrm{mV} \cdot \mathrm{s}^{-1}}$ & $415^{*}$ & $3140^{*}$ \\
$C_{\mathrm{CV} \text { при } 10 \mathrm{mV} \cdot \mathrm{s}^{-1}}$ & $60^{*}$ & 1640 \\
$C_{\mathrm{GCD}}$ при $0.15 \mathrm{~A} \cdot \mathrm{g}^{-1}\left(1.25 \mathrm{~A} \cdot \mathrm{g}^{-1}\right)^{* *}$ & 215 & 1110
\end{tabular}

* Значения емкости определены при токе, соответствующем пику на $I-V$ кривых циклической вольтамперометрии.

** В скобках приведены значения тока в расчете на массу активного вещества (NiNPs).

сенные к полной массе электрода и к суммарной массе NiNPs, приведены в таблице.

Композит bioC/NiNPs демонстрирует высокую максимальную емкость $C_{\mathrm{CV}}=3140 \mathrm{~F} \cdot \mathrm{g}^{-1}$, отнесенную к массе активного действующего вещества композита - наночастиц $\mathrm{Ni}$, которая сравнима или даже превышает таковую для электродов, изготовленных из таких гибридных материалов, как графеновые слои/пленка $\mathrm{NiO}\left(324 \mathrm{~F} \cdot \mathrm{g}^{-1}\right), \mathrm{Ni}(\mathrm{OH})_{2} / \mathrm{Ni} /$ графен $\left(2609 \mathrm{~F} \cdot \mathrm{g}^{-1}\right)[16], \mathrm{Ni}(\mathrm{OH})_{2} / \mathrm{CNT}$ (углеродные нанотрубки)/графен $\left(3300 \mathrm{~F} \cdot \mathrm{g}^{-1}\right)[17]$.

Максимальная электрохимическая емкость, полученная для монолитного электрода bioC/NiNPs $\left(C_{\mathrm{CV}}=\right.$ $=415 \mathrm{~F} \cdot \mathrm{g}^{-1}$ при $\left.1 \mathrm{mV} \cdot \mathrm{s}^{-1}\right)$, значительно превышает таковые для других монолитных биоуглеродов или гибридных структур на их основе: биоуглерода, полученного из древесины бука и активированного потоком водного пара $\left(C_{\mathrm{CV}}=200 \mathrm{~F} \cdot \mathrm{g}^{-1}\right.$ при $\left.1 \mathrm{mV} \cdot \mathrm{s}^{-1}\right)$ [7], частично графитизированного биоуглерода с использованиeм Fe-содержащего катализатора $\left(C_{\mathrm{CV}}=95 \mathrm{~F} \cdot \mathrm{g}^{-1}\right.$ при $\left.1 \mathrm{mV} \cdot \mathrm{s}^{-1}\right)$ [8], гибридных структур на основе биоуглерода - bioC/ $\mathrm{MnO}_{2}\left(C_{\mathrm{CV}}=18 \mathrm{~F} \cdot \mathrm{g}^{-1}\right.$ при $\left.1 \mathrm{mV} \cdot \mathrm{s}^{-1}\right)[18]$ и bioC $/ \mathrm{NbO}_{2}\left(C_{\mathrm{CV}}=104 \mathrm{~F} \cdot \mathrm{g}^{-1}\right.$ при $1 \mathrm{mV} \cdot \mathrm{s}^{-1}[19]$. Полученное максимальное значение $C_{\mathrm{CV}}$ для композита bioC/NiNPs более чем вдвое превышает величину удельной емкости электрода, изготовленного из одного из лучших коммерческих активированных углеродов углеродного порошка Maxsorb (90\% активной массы) и связующей добавки (10 mass \% поливинилиденфторида, PVDF $) \quad\left(C_{\mathrm{CV}}=190 \mathrm{~F} \cdot \mathrm{g}^{-1}\right.$ при $\left.2 \mathrm{mV} \cdot \mathrm{s}^{-1}\right)$ [20]. Порошок Maxsorb (Япония) имеет очень высокую удельную площадь поверхности $3500 \mathrm{~m}^{2} \cdot \mathrm{g}^{-1}$ и считается одним из наиболее эффективных активированных углей для изготовления электродов для промышленных суперконденсаторов [20].

Эксперименты с длительным циклированием электродного потенциала методом циклической вольтамперометрии продемонстрировали хорошую стабильность электрохимических характеристик монолитного электрода bioC/NiNPs: первоначальное значение емкости сначала, в течение первых 100 циклов работы, несколько понижалось, затем стабилизировалось и далее изменя- лось слабо (рис. 3). После 1000 циклов вольтамперометрии со скоростью сканирования $10 \mathrm{mV} \cdot \mathrm{s}^{-1}$ удельная электрохимическая емкость сохранялась на уровне более $85 \%$ от исходного значения (рис. 3 ).

Таким образом, в работе простым, экологически совместимым и дешевым способом был получен монолитный композит bioc/NiNPs, демонстрирующий высокие электрохимические характеристики, что предполагает высокий потенциал его использования в качестве монолитного электродного материала при разработке суперконденсаторов.

\section{Благодарности}

Исследования методом ПЭМ и РСА выполнены с использованием оборудования федерального ЦКП „Материаловедение и диагностика в передовых технологиях“.

\section{Конфликт интересов}

Авторы заявляют, что у них нет конфликта интересов.

\section{Список литературы}

[1] Wang G., Zhang L., Zhang. J. // Chem. Soc. Rev. 2012. V. 41. P. 797-828.

[2] Wang Y., Song Y., Xia Y. // Chem. Soc. Rev. 2016. V. 45. P. 5925-5950.

[3] Saliger R., Fischer U., Herta C., Fricke J. // J. Non-Cryst. Solids. 1998. V. 225. P. 81-85.

[4] Hebalkar N., Arabale G., Sainkar S.R., Pradhan S.D., Mulla I.S., Vijayamohanan K., Ayyub P., Kulkarni S.K. // J. Mater. Sci. 2005. V. 40. P. 3777-3782.

[5] Fan L.Z., Hu Y.S., Maier J., Adelhelm P., Smarsly B., Antonietti M. // Adv. Funct. Mater. 2007. V. 17. P. 3083-3087.

[6] Ruiz V., Blanco C., Granda M., Menéndez R., Santamaría R.J. // Appl. Electrochem. 2007. V. 37. P. 717721.

[7] Orlova T.S., Shpeizman V.V., Glebova N.V., Nechitailov A.A., Spitsyn A.A., Ponomarev D.A., Gutierrez-Pardo A., RamirezRico J. // Rev. Adv. Mater. Sci. 2018. V. 55. P. 50-60.

[8] Gutierrez-Pardo A., Ramírez-Rico J., Cabezas-Rodríguez R., Martínez-Fernandez J. // J. Power Sources. 2015. V. 278. P. 18-26. 
[9] Liu M.C., Kong L.B., Zhang P., Luo Y.C., Kang L. // Electrochim. Acta. 2012. V. 60. P. 443-448.

[10] Taer E, Yusriwandi, Taslim R., Syam I.D.M., Deraman M. // KnE Eng. 2016. V. 2016. P. 1-6. DOI: 10.18502/keg.v1i1.499

[11] Zhi M., Xiang Ch., Li J., Li M., Wu N. // Nanoscale. 2013. V. 5. P. $72-88$.

[12] Рипан Р., Четяну И. Неорганическая химия. М.: Мир, 1972. T. $2.871 \mathrm{c}$.

[13] Gutierrez-Pardo A., Ramirez-Rico J., de Arellano-Lopez A.R., Martinez-Fernandez J. // J. Mater. Sci. 2014. V. 49. P. 7688 7696.

[14] Grdeń M., Alsabet M., Jerkiewicz G. // ACS Appl. Mater. Interfaces. 2012. V. 4. P. 3012-3021.

[15] Уголев Б.Н. Древесиноведение с основами лесного товароведения. 4-е изд. М: ГОУ ВПО МГУЛ, 2005. $340 \mathrm{c.}$

[16] Liu T., Shao G., Ji M. / Mater. Lett. 2014. V. 122. P. 273-276.

[17] Tang Z., Tang C.H., Gong H. // Adv. Funct. Mater. 2012. V. 22. P. $1272-1278$.

[18] Gutierrez-Pardo A., Lacroix B., Martinez-Fernandez J., Ramirez-Rico J. // ACS Appl. Mater. Interfaces. 2016. V. 8. P. 30890-30898.

[19] Fiz R., Appel L., Gutierrez-Pardo A., Ramirez-Rico J., Mathur S. // ACS Appl. Mater. Interfaces. 2016. V. 8. P. 21423-21430.

[20] Raymundo-Pinero E., Leroux F. // Adv. Mater. 2006. V. 18. P. 1877-1882. 